\title{
Translation, cross-cultural adaptation and validation of the vitiligo-specific health-related quality of life instrument (VitiQoL) into Brazilian Portuguese*
}

\author{
Juliana Catucci Boza ${ }^{1}$ \\ Amanda Fabbrin ${ }^{1}$ \\ Natalia Giongo ${ }^{1}$
}

\author{
Roopal V Kundu ${ }^{2}$ \\ Roberta Horn ${ }^{1}$ \\ Tania Ferreira Cestari ${ }^{1}$
}

DOI: http:/ / dx.doi.org/10.1590/abd1806-4841.20153684

\begin{abstract}
A bstract: BACKGROUND: Vitiligo, although asymptomatic, highly compromises patients' quality of life (QoL). Therefore, an adequate evaluation of QoL is essential.

Oвјестіves: Translation, cultural adaptation and validation of VitiQol (Vitiligo-specific health-related quality of life instrument) into Brazilian Portuguese.

Methods: The study was conducted in two stages; the first stage was the translation and cultural/linguistic adaptation of the instrument; the second stage was the instrument's validation.

RESUlTs: The translated VitiQol showed high internal consistency (Cronbach alpha $=0.944$ ) and high test-retest reliability and intraclass correlation coefficient $=0.95$ (CI 95\% $0.86-0.98), p<0.001$. There was no statistically significant difference between the means of the first completion of the VitiQoL questionnaire and the retest, $\mathrm{p}=0.661$. There was a significant correlation between VitiQoL and DLQI $(r=0.776, p<0.001)$ and also between VitiQoL-PB and subjects' assessment of the severity of their disease $(r=0.702, p<0.001)$.

CONCLUSIONS: The impact of vitiligo on the QoL of Brazilian patients can be assessed by a specific questionnaire.

Keywords: Indicators of quality of life; Quality of life; Sickness impact profile; Vitiligo
\end{abstract}

\section{INTRODUCTION}

Vitiligo is an acquired pigmentary disorder, characterized by achromatic spots due to a loss of melanocytes. Its prevalence ranges between $0.5 \%$ and $1 \%$ worldwide. Gujarat, India, is considered to be the place with the highest prevalence of vitiligo: approximately $8.8 \% .{ }^{1}$ The average age of onset is 22 years in the United States and India, 24 years in Brazil and 25 years in England, and half of the patients develop the disease before 20 years of age. .,2,3 $^{2}$

Adults and children of both genders are equally affected, but some studies indicate a slight preponderance of cases among females, possibly because women seek medical care more often than men due to the secondary psychosocial consequences. ${ }^{3,4,5,6}$ There is no predilection for skin type or race. ${ }^{1}$
There are genetic factors involved in its etiopathogenesis, and the relative risk of vitiligo in first-degree relatives is estimated as seven to 10 times greater than in the general population. ${ }^{3,7}$ Other aspects involved include autoimmunity, intrinsic defects of melanocytes and T-cells, and oxidative stress. ${ }^{8-11}$

Many dermatological diseases are characterized by compromising patients' physical and relational well-being. For this reason, the assessment of quality of life (QoL) is of fundamental importance. ${ }^{12,13}$ Vitiligo, although asymptomatic, highly compromises QoL. It affects patients' lives in many ways, being sometimes psychologically devastating. The condition compromises self-esteem, body image and social life. Individuals with vitiligo suffer social discrimination and stigmatization, which result in significant chang-

Received on 08.05.2014

Approved by the Advisory Board and accepted for publication on 07.07.2014

Study conducted at the Dermatology Service of the Hospital de Clínicas de Porto Alegre (HCPA), Postgraduate Program - Children's and Adolescent's HealthSchool of Medicine, Universidade Federal do Rio Grande do Sul (UFRGS) - Porto Alegre (RS), Brazil.

Financial Support: None.

Conflict of Interest: None.

Universidade Federal do Rio Grande do Sul (UFRGS) - Porto Alegre (RS), Brazil.

Northwestern University/Feinberg School of Medicine - Chicago, USA.

C2015 by Anais Brasileiros de Dermatologia 
es in their lifestyles: from the choice of clothing, use of sunscreen and cosmetic camouflage of the lesions to the avoidance of social events or outdoor activities. ${ }^{14-17}$

Recently, a specific questionnaire for vitiligo has been developed and validated in the English language: the Vitiligo-specific health-related quality of life instrument (VitiQoL) ${ }^{17}$ To this date, there were no instruments in Brazilian Portuguese to assess the QoL in vitiligo.

The VitiQoL is a questionnaire of 15 items, with item scores from 0 (never) to 6 (all the time). It yields a total score from 0 to 90 . Moreover, it presents a personal assessment of the severity of vitiligo, using a scale ranging from 0 (no skin involvement) to 6 (worst case), which corresponds to the 16th question of the VitiQoL questionnaire. The questionnaire shows to be a promising clinical and epidemiological study instrument, and a powerful marker of outcome. ${ }^{17}$

The aim of this study was to perform the translation, cross-cultural adaptation and validation of the VitiQoL into Brazilian Portuguese (VitiQoL-PB).

\section{METHODS}

The author of the VitiQoL questionnaire authorized its translation, cross-cultural adaptation and validation. The study was conducted in two stages: the first stage was the translation and cultural/linguistic adaptation of the instrument; the second stage was the instrument's validation. This is an observational study. Subjects were divided into two groups: cross-sectional and follow-up (retest). Subjects were selected from a Dermatological Outpatient Clinic from Hospital de Clínicas de Porto A legre. In this study, we used convenience sampling of consecutive cases. Inclusion criteria were: older than 18 years of age; able to read and understand Brazilian Portuguese; diagnosis of vitiligo confirmed by a dermatologist. Exclusion criteria were: presence of chronic, non-dermatological disease or other concomitant dermatological disease.

In the first stage (translation and cross-cultural adaptation), two independent translators performed the literal translation of the VitiQoL instrument from English into Portuguese. This version was later reviewed by a bilingual group, composed of health professionals. Next, 10 subjects with vitiligo were asked to answer the questionnaire and make suggestions for its clarity and understanding. After repeat review by the same bilingual group, this new version of the questionnaire was translated into English and sent to the author of the original questionnaire for approval. This stage took place from January to June 2013.

Based on the original study and the WHO recommendations for the development of quality of life questionnaires, a specific questionnaire on demographic data, the VitiQoL questionnaire and a gener- ic instrument for dermatological diseases previously validated for Portuguese, the DLQI (Dermatology Life Quality Index), were administered to 74 subjects. In addition, subjects made a personal assessment of their severity of vitiligo, using a scale ranging from 0 (no skin involvement) to 6 (most severe cases), which corresponded to the 16th question of the VitiQoL-PB questionnaire.

For test-retest reliability, the sample was calculated based on the studies reliability graph, using a reliability coefficient (Cronbach's coefficient) of 0.80 and a confidence interval of 0.05 . Statistical analysis was performed using SPSS (SPSS Inc. Chicago, II, version 18.0 for Windows). The reliability of the instrument was demonstrated through the analysis of internal consistency using Cronbach's coefficient of reliability. Test-retest reliability was assessed by intraclass correlation coefficient (ICC) and Student $t$ test for paired samples. The PB-VitiQoL and DLQI were compared using the Pearson correlation coefficient. General data were analyzed using descriptive statistics (mean and standard deviation for quantitative variables with symmetric distribution; median and interquartile range for variables with asymmetric distribution; and frequencies and percentages for categorical variables). The study project was approved by the Research Ethics Committee and all subjects signed an informed consent.

\section{RESULTS}

The questionnaire was completed by 74 subjects. For analysis of reproducibility (test-retest reliability), two to four weeks after the first interview, a subgroup of subjects, corresponding to $20 \%$ of the sample, completed the VitiQol-PB questionnaire again.

Subjects' demographic and clinical characteristics are described in table 1. The translated VitiQol showed high internal consistency (Cronbach alpha $=0.944)$ and high test-retest reliability, with an intraclass correlation coefficient of 0.95 (CI 95\% 0.86 - 0.98), $\mathrm{p}<0.001$. There was no statistically significant difference between the means of the first completion of the VitiQoL questionnaire and the retest, $\mathrm{p}=0.661$ (Graph 1) $\mid$. The $95 \%$ interval of agreement between the test and retest was -25.46 to 22.71 .

The single item that most contributed to the total score of VitiQoL-PB was related to the frustration about the skin condition (question 2). Other items that significantly contributed to the final scores were: feeling bothered by the appearance of the skin (question 1 ), worry about what other people think (question 5), fear of criticism (question 6), embarrassment or inhibition because of the skin (question 7), social or leisure activities (question 9), emotional well-being (question 10). In general, we found that all items contributed to the final score (Table 2). 
The average VitiQoL-PB score was 40.04+27.32; while the median DLQI was 3 (interquartile range P25 $=1$ and P75 =7). The average patient assessment score for severity of illness was $3.64+1.87$ (Figure 1).

There was a significant correlation between VitiQoL and DLQI $(\mathrm{r}=0.776, \mathrm{p}<0.001)$ and also between VitiQoL-PB and subjects' assessment of the severity of their disease $(\mathrm{r}=0.702, \mathrm{p}<0.001)$. We also found a good correlation between the total DLQI and subjects' assessment of the severity of their disease $(r=0.673$, $p$ $<0.001$ ) (Graph 2).

TABLE 1: Clinical and demographic data

\begin{tabular}{|c|c|c|}
\hline & \multicolumn{2}{|c|}{$\begin{array}{l}\text { M ean } \\
\text { (standard deviation) }\end{array}$} \\
\hline Age & \multicolumn{2}{|c|}{$44.70(17.107)$} \\
\hline Age of onset & \multicolumn{2}{|c|}{31 (median) } \\
\hline Duration of the disease & \multicolumn{2}{|c|}{11 (median) } \\
\hline & $\mathbf{N}$ & $(\%)$ \\
\hline \multicolumn{3}{|l|}{ Gender } \\
\hline Male & 24 & $(32.4)$ \\
\hline Female & 50 & $(67.6)$ \\
\hline \multicolumn{3}{|l|}{ Skin type } \\
\hline II & 12 & $(16.2)$ \\
\hline III & 31 & $(41.9)$ \\
\hline IV & 26 & $(35.1)$ \\
\hline V & 5 & $(6.8)$ \\
\hline \multicolumn{3}{|l|}{ Educational level } \\
\hline Incomplete primary education & 21 & $(28.4)$ \\
\hline Complete primary education & 3 & $(4.1)$ \\
\hline Incomplete secondary education & 13 & $(17.6)$ \\
\hline Complete secondary education & 12 & $(16.2)$ \\
\hline Incomplete higher education & 12 & $(16.2)$ \\
\hline Complete higher education & 13 & $(17.6)$ \\
\hline \multicolumn{3}{|l|}{ M arital status } \\
\hline Married & 27 & $(36.4)$ \\
\hline Divorced/ Separated & 12 & $(16.2)$ \\
\hline Widowed & 6 & $(8.3)$ \\
\hline Single & 29 & $(39.1)$ \\
\hline \multicolumn{3}{|l|}{ Income } \\
\hline up to 500.00 & 3 & $(4.1)$ \\
\hline $500.00-1,000.00$ & 20 & $(27)$ \\
\hline $1,000.00-3,000.00$ & 33 & $(44.6)$ \\
\hline$>3,000.00$ & 16 & $(21.6)$ \\
\hline Was unable to report & 2 & $(2.7)$ \\
\hline
\end{tabular}

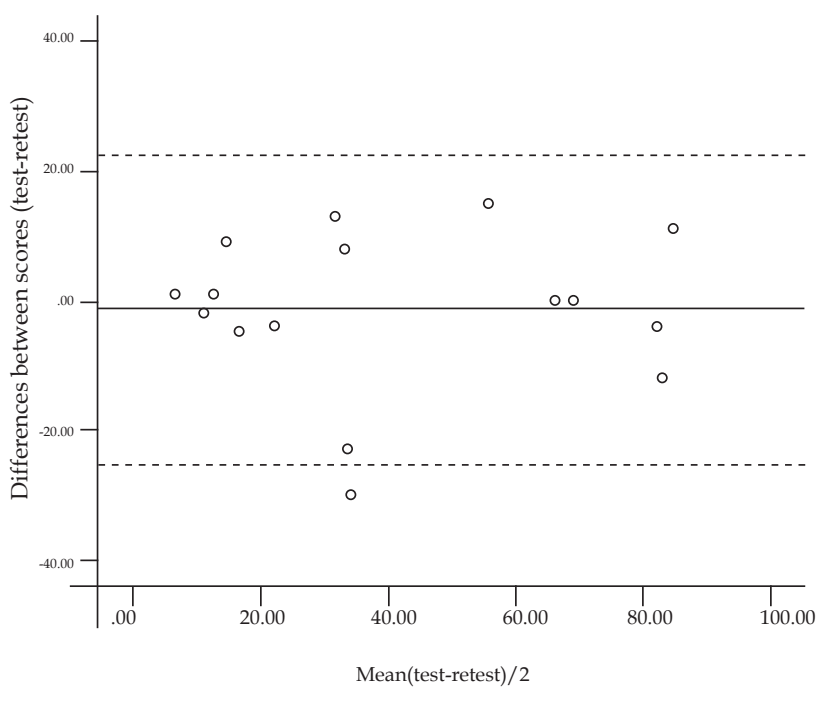

GraPH 1: Clinical and demographic data Bland and Altman's graph showing agreement between test and retest scores. The solid line shows the difference between the means of the test and the retest; the dotted line shows the $95 \%$ limits of agreement (mean difference $\pm 1.96 \mathrm{SD}$ )

TABLE 2: Correlation between items and between the items with the final score

\begin{tabular}{lcc}
\hline Item & $\begin{array}{l}\text { Correlation } \\
\text { between items }\end{array}$ & $\begin{array}{c}\text { Correlation } \\
\text { between the } \\
\text { items and } \\
\text { the final score }\end{array}$ \\
\hline 1- Bother & $0.27-0.84$ & 0.83 \\
2 - Frustration & $0.28-0.85$ & 0.85 \\
3 - Difficulty showing & $0.25-0.67$ & 0.69 \\
affection & & \\
4- Daily activities & $0.29-0.75$ & 0.77 \\
5 - Worry about what & $0.17-0.84$ & 0.81 \\
other people think & & \\
6 - Fear of criticism & $0.17-0.84$ & 0.82 \\
7 - Embarrassment & $0.35-0.85$ & 0.83 \\
or inhibition & & \\
8 - Type of clothing & $0.25-0.68$ & 0.72 \\
9 - Social and leisure & $0.30-0.75$ & 0.81 \\
activities & & \\
10- Emotional well-being & $0.21-0.75$ & 0.83 \\
11- Physical health as & $0.24-0.71$ & 0.70 \\
a whole & & \\
12 - Care with personal & $0.24-0.59$ & 0.66 \\
appearance & & 0.41 \\
13 - Sun protection care & $0.12-0.35$ & \\
14- Making new friends & $0.12-0.67$ & \\
15- Disease progression & $0.24-0.59$ & \\
& & \\
\hline
\end{tabular}




\section{Figure 1: VitiQoL PB}

The purpose of these questions is to assess whether the aspect of your skin affected your life during the last month.

DURING THE LAST MONTH, from 0 (not at all/ not applicable) to 6 (very much):

1. $D$ id you feel bothered by the appearance of your skin?

2. Did you feel frustrated about your skin condition?

3. Did you feel difficulty in showing affection because of your skin condition?

4. H as your skin condition affected your daily activities?

5. While talking to someone, did you worry about what people might be thinking about you?

6. Wereyou afraid that people would criticize you?

7. Did you feel embarrassed or inhibited because of your skin?

8. $D$ id the appearance of your skin influence your choice of clothing?

9. Did your skin condition affect your social or leisure activities?

10. Did your skin condition affect your emotional well-be ing?

11. Did your skin condition affect your physical health (as a whole)?

12. Did your skin condition influence your care with personal appearance (for instance, haircut or use of cosmetic products)?

13. Did your skin condition influence your sun protection care during leisure activities (for instance, limiting the time of exposure to the sun during peak hours, staying out of the sun, wearing a hat, long sleeves or pants)?

14. Did your skin condition affect the possibility of making new friends?

15. Did you worry about disease progression to other body parts?

16. Please rate how severeyou think your skin condition is: Severity of skin condition

\begin{tabular}{|l|l|l|l|l|l|l|}
\hline 0 & 1 & 2 & 3 & 4 & 5 & 6 \\
\hline
\end{tabular}

Reproduced with permission of the authors

ALL RIGHTS RESERVED

(C) Lilly E, Kundu RV 2012.

Any unauthorized use or reproduction of this document is strictly prohibited.

\section{DISCUSSION}

The development and validation of dermatology-specific QoL questionnaires is recent. ${ }^{18,19}$ For the evaluation of a specific dermatosis, there is a tendency to combine two questionnaires: one generic questionnaire and another disease-specific dermatologic questionnaire, comparing both scores. ${ }^{20}$ Disease-specific instruments are already available for several chronic dermatoses, such as atopic dermatitis, acne and melasma. ${ }^{21-23}$

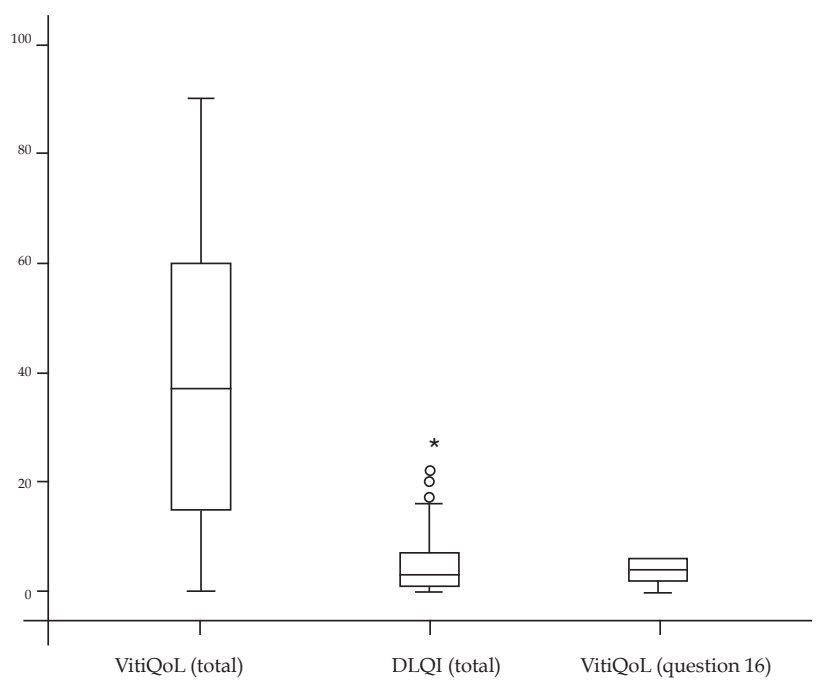

G RAPH 2 : Correlation between VitiQoL-PB, DLQI and question 16 of VitiQoL (self-reported severity of vitiligo)

The absence of a vitiligo-specific questionnaire for the assessment of QoL led to the use of the general dermatology questionnaires, such as DLQI and Skindex-16. However, they do not seem to be sensitive enough for the assessment of an asymptomatic disease such as vitiligo. ${ }^{24}$ For conditions like acne and psoriasis, it has been shown that specific questionnaires better reflect QoL. ${ }^{25,26}$ In addition, they make it possible to correlate clinical and demographic aspects of a specific population with QoL. $27,28,29$

The VitiQoL-PB Cronbach's alpha coefficient was similar to the coefficient of the original questionnaire (original VitiQoL Cronbach's alpha $=0.935$ ), which demonstrates the reliability of the instrument. Additionally, it showed a strong correlation with both the subjects' assessment of disease severity and the DLQI. In the original VitiQoL, one of the limitations highlighted by the authors was the fact that no assessment of test-retest reliability had been carried out. In our study, 16 subjects ( $21 \%$ of the sample) completed the VitiQoL-PB a second time, confirming the high test-retest reliability with an intraclass correlation coefficient (ICC) of 0.95 (95\% CI, 0.86 to 0.98 ). The intraclass correlation coefficient ensures the reproducibility of the questionnaire, and ICC values $\geq 0.75$ are considered excellent.

\section{CONCLUSION}

There are little data on the quality of life of patients with vitiligo in Brazil. Most studies have been conducted in children, by using the Children's 
Dermatology Life Quality Index..$^{30,31}$ Studies conducted with adults generally use the DLQI and the SF-36 (Medical Outcomes Study 36-item Short-Form Health Survey). ${ }^{32,33}$ Moving forward, the impact of vitiligo on the quality of life of Brazilian patients can be assessed using a disease-specific questionnaire, which will contribute to a more complete and reliable evaluation of these patients.

\section{REFERENCE}

1. Alikhan A, Felsten LM, Daly M, Petronic-Rosic V. Vitiligo: a comprehensive overview Part I. Introduction, epidemiology, quality of life, diagnosis, differential diagnosis, associations, histopathology, etiology, and work-up. J Am Acad Dermatol. 2011;65:473-91.

2. Barona Ml, Arrunátegui A, Falabella R, Alzate A. An epidemiologic case-control study in a population with vitiligo. J Am Acad Dermatol. 1995;33:621-5.

3. Tarlé RG, Nascimento LM, Mira MT, Castro CC. Vitiligo--part 1. An Bras Dermatol. 2015;90:461-70.

4. Sehgal VN, Srivastava G. Vitiligo: compendium of clinico-epidemiological features. Indian J Dermatol Venereol Leprol. 2007;73:149-56.

5. Liu JB, Li M, Yang S, Gui JP, Wang HY, Du WH, et al. Clinical profiles of vitiligo in China: an analysis of 3742 patients. Clin Exp Dermatol. 2005;30:327-31.

6. Nunes DH, Esser LM. Vitiligo epidemiological profile and the association with thyroid disease. An Bras Dermatol. 2011;86:241-8.

7. Nath SK, Majumder PP, Nordlund JJ. Genetic epidemiology of vitiligo: multilocus recessivity cross-validated. Am J Hum Genet. 1994;55:981-90.

8. Nejad SB, Qadim HH, Nazeman L, Fadaii R, Goldust M. Frequency of autoimmune diseases in those suffering from vitiligo in comparison with normal population. Pak J Biol Sci. 2013;16:570-4.

9. Ingordo V1, Cazzaniga S, Raone B, Digiuseppe MD, Musumeci ML, Fai D, et al. Circulating Autoantibodies and Autoimmune Comorbidities in Vitiligo Patients: A Multicenter Italian Study. Dermatology. 2014;228:240-9.

10. Taieb A, Picardo M. Clinical practice: vitiligo. N Engl J Med. 2009;360:160-9

11. Laddha NC, Dwivedi M, Mansuri MS, Singh M, Gani AR, Yeola AP, et al. Role of oxidative stress and autoimmunity in onset and progression of vitiligo. Exp Dermatol. 2014;23:352-3.

12. Wachholz PA, Masuda PY, Nascimento DC, Taira CM, Cleto NG. Quality of life profile and correlated factors in chronic leg ulcer patients in the mid-west of São Paulo State, Brazil. An Bras Dermatol. 2015;90:73-81.

13. Kamamoto Cde S, Hassun KM, Bagatin E, Tomimori J. Acne-specific quality of life questionnaire (Acne-QoL): translation, cultural adaptation and validation into Brazilian-Portuguese language. An Bras Dermatol. 2015;90:83-90.

14. Silverberg JI, Silverberg NB. Association between vitiligo extent and distribution and quality-of-life impairment. JAMA Dermatol. 2013;149:159-64.

15. Teovska Mitrevska N, Eleftheriadou V, Guarneri F. Quality of life in vitiligo patients. Dermatol Ther. 2012;25:S28-31.

16. Eleftheriadou V, Thomas KS, Whitton ME, Batchelor JM, Ravenscroft JC. Which outcomes should we measure in vitiligo? Results of a systematic review and a survey among patients and clinicians on outcomes in vitiligo trials. $\mathrm{Br} J$ Dermatol. 2012;167:804-14

17. Lilly E, Lu PD, Borovicka JH, Victorson D, Kwasny MJ, West DP, et al. Development and validation of a vitiligo-specific quality-of-life instrument (VitiQoL). J Am Acad Dermatol. 2013:69:e11-8.

18. Both H, Essink-Bot ML, Busschbach J, Nijsten T. Critical review of generic and dermatology-specific health-related quality of life instruments. J Invest Dermatol. 2007;127:2726-39.

19. Finlay AY, Khan GK. Dermatology Life Quality Index (DLQI)--a simple practical measure for routine clinical use. Clin Exp Dermatol. 1994;19:210-6.

20. De Korte J, Mombers FM, Sprangers MA, Bos JD. The suitability of quality-oflife questionnaires for psoriasis research: a systematic literature review. Arch Dermatol. 2002;138:1221-7.
Vitiligo is a chronic disease and, although it is asymptomatic, it highly compromises patients' quality of life (QoL). The translation, cross-cultural adaptation and validation of the VitiQoL-PB will not only assist in treatment evaluation and in the comparison of results of studies conducted in different regions of Brazil, but also allow the correlation with international data.
21. Whalley D, McKenna SP, Dewar AL, Erdman RA, Kohlmann T, Niero M, et al. A new instrument for assessing quality of life in atopic dermatitis: international development of the Quality of Life Index for Atopic Dermatitis (QoLIAD). Br J Dermatol. 2004;150:274-83.

22. Fehnel SE, McLeod LD, Brandman J, Arbit DI, McLaughlin-Miley CJ, Coombs JH, et al. Responsiveness of the Acne-Specific Quality of Life Questionnaire (AcneQoL) to treatment for acne vulgaris in placebo-controlled clinical trials. Qual Life Res. 2002;11:809-16.

23. Balkrishnan R, McMichael AJ, Camacho FT, Saltzberg F, Housman TS, Grummer $\mathrm{S}$, et al. Development and validation of a health-related quality of life instrument for women with melasma. Br J Dermatol. 2003:149:572-7.

24. Gawkrodger DJ, Ormerod AD, Shaw L, Mauri-Sole I, Whitton ME, Watts MJ, et al. Guideline for the diagnosis and management of vitiligo. Br J Dermatol. 2008:159:1051-76.

25. McKenna SP, Cook SA, Whalley D, Doward LC, Richards HL, Griffiths CE, et al. Development of the PSORIQoL, a psoriasis- specific measure of quality of life designed for use in clinical practice and trials. Br J Dermatol. 2003;149:323-31.

26. Gupta MA, Johnson AM, Gupta AK. The development of an Acne Quality of Life scale: reliability, validity, and relation to subjective acne severity in mild to moderate acne vulgaris. Acta Derm Venereol. 1998;78:451-6.

27. Boza JC, Basra MK, Vanin RC, Carvalho RR, Weber MB, Cestari TF. Translation into Brazilian Portuguese and validation of the psoriasis family index. An Bras Dermatol. 2013:88:484-4.

28. Freitag FM, Cestari TF, Leopoldo LR, Paludo P, Boza JC. Effect of melasma on quality of life in a sample of women living in southern Brazil. J Eur Acad Dermatol Venereol. 2008;22:655-62.

29. Cestari TF, Hexsel D, Viegas ML, Azulay L, Hassun K, Almeida AR, et al. Validation of a melasma quality of life questionnaire for Brazilian Portuguese language: the MelasQoL-BP study and improvement of QoL of melasma patients after triple combination therapy. Australas J Dermatol. 2006;156:13-20.

30. Weber MB, Lorenzini D, Reinehr CP, Lovato B. Assessment of the quality of life of pediatric patients at a center of excellence in dermatology in southern Brazil. An Bras Dermatol. 2012;87:697-702.

31. Manzoni AP, Pereira RL, Townsend RZ, Weber MB, Nagatomi AR, Cestari TF. Assessment of the quality of life of pediatric patients with the major chronic childhood skin diseases. An Bras Dermatol. 2012;87:361-8.

32. Ludwig MW, Oliveira Mda S, Muller MC, Moraes JF. Quality of life and site of the lesion in dermatological patients. An Bras Dermatol. 2009;84:143-50.

33. Ciconelli RM, Ferraz MB, Santos W, Meinão I, Quaresma MR. Tradução para a língua portuguesa e validação do questionário genérico de avaliação de qualidade de vida SF-36 (Brasil SF-36). Rev Bras Reumatol. 1999;39:143-50.

\author{
M AILING ADDRESS: \\ Juliana Catucci Boza \\ Rua Ramiro Barcelos, 2350 - Santa Cecília \\ 90035-903 - Porto A legre - RS \\ Brazil \\ E-mail: juliana_boza@yahoo.com.br
}

How to cite this article: Boza JC, Kundu RV, Fabbrin A, Horn R, Giongo N, Cestari TF. Translation, cross-cultural adaptation and validation of the vitiligo-specific health-related quality of life instrument (VitiQoL) into Brazilian Portuguese. An Bras Dermatol. 2015;90(3):358-62. 